power to serve that purpose. The International Harvester Company has found, however, that in Iowa and regions further south, grasshoppers cut the bands of the flax fiber twine in the field so badly as to really prohibit its use. That Company was trying numerous chemical treatments at harvest time in 1907 upon the fiber in a search for something distasteful to that class of insects.

It is not certain that a demand for flax fiber of the coarse short grade will be immediately forthcoming; and it is likely that labor prices and business conditions must change before a demand for fine fiber flax will occur in this country. It seems, certain, however, that a suitable type of flax for producing fine and long fiber can be produced by breeding and turned over to the grower as soon as the manufacturer can offer him a remunerative price for it.

\title{
REPORT OF THE COMMITTEE ON BREEDING VEGETABLES.
}

W. W. TracY, SR., Washington, D. C., Chairman,

Prof. N. E. Hansen, Brookings, S. D., C. N. Kefney, Le Roy, N. Y.,

Prof. W. M. Munson, Morgantown, Dr. Byron D. Halstead, New W. Va.

Mr. S. W. Olliver, Washington, D. C., Leonard H. Vaugha, Chicago, Ill.,

H. Brunsuick, $N$. J.' Fullerton, Wading River, Long Island.

OrJects: To investigate and report on methods of improving vegetables by breeding; and to encourage the production of improved purebred varieties of vegetables suited to each condition of climate, soil, use, and market.

\section{(Report submitted by the Chairman.)}

\section{EXISTING CONDITIONS.}

We have but very little actual knowledge as to the practical usefulness of different characteristics, and still less as to the correlation of those discernible to the eye with those not so discernible, but of even greater practical value as adapting the plant to different cultural and market conditions and uses. Our record of modifications which have been developed from time to time is very imperfect and incomplete, and in consequence breeders are constantly presenting as new varieties, forms which in previous trials had proved to be of so little practical value that they had dropped out of common knowledge and cultivation.

The number of varietal names in more or less common use is very much greater than that of the really distinct and useful varieties. One reason for this is the use of distinct varietal names to denote simply the relative purity and quality of different stocks which are really the same variety. Another is the want of knowledge as to the name by which any given variation is or has been known. From this and other causes there is a want of uniformity in the names by which each distinct variation is known as well as in the variation which any given name shall stand for. 
There is a general want of appreciation of the relative practical value of variation and uniformity. Many breeders devote time and skill to the origination of new and distinct variations with little regard to their practical value, which could be much more profitably expended in the development, by selection or otherwise, of more uniform stocks of the varieties we now have.

\section{SUGGESTIONS FOR IMPROVEMENT.}

Many varietal tests of commercial stocks should be made under different environmental conditions, but with such uniformity of method, both as to observation and record, that the different results obtained are easily comparable. In such trials the varietal characteristics already developed should be carefully studied to ascertain their relation to each other, and their practical value for different conditions and uses. Full descriptions of these variations should be made, and the name, or names by which they are known should be recorded. We think this can only be accomplished by active cooperation of our experiment stations, seedsmen and seed breeders, the use of uniform descriptive forms and cultural records, and the filing in some accessible place of full descriptions of the exact varietal character of the stocks which it is proposed to designate by new varietal names.

Such descriptive records should be referred to some competent and recognized authority for classification, and the registration of the name by which each distinct variation should be known. Different stocks of practically the same variation might be distinguished by some qualifying name, and such descriptive records should be carefully studied by breeders before the naming and dissemination of any new or supposedly new variation.

Breeders should devote the larger proportion of their efforts towards securing the higher and more uniform development of the most practically useful qualities rather than towards mere variation. Greater attention should be given to the selection and breeding from prepotent individuals having to a high degree the exact varietal characteristic desired. In crossing, the parents should be selected with reference to the development of some definite characteristic which is believed to be of practical value; or, when made for the sake of greater vigor, they and all the subsequent selections should aim at the development of a uniform and more vigorous stock of some existing variation of proven practical value rather than towards one which is simply different and of doubtful usefulness. It is not proposed that all effort for the development of distinctly new characteristics should be abandoned, but that it should be made secondary to the higher and more uniform development of the most practically usefui characteristics of existing sorts, or of some definite quality of known practical value. 